\title{
The diminished effect of index rebalances
}

Article

Accepted Version

Kappou, K. (2018) The diminished effect of index rebalances. Journal of Asset Management, 19 (4). pp. 235-244. ISSN 1470-8272 doi: https://doi.org/10.1057/s41260-018-0077-8 Available at https://centaur.reading.ac.uk/76714/

It is advisable to refer to the publisher's version if you intend to cite from the work. See Guidance on citing.

To link to this article DOI: http://dx.doi.org/10.1057/s41260-018-0077-8

Publisher: Palgrave Macmillan

All outputs in CentAUR are protected by Intellectual Property Rights law, including copyright law. Copyright and IPR is retained by the creators or other copyright holders. Terms and conditions for use of this material are defined in the End User Agreement.

\section{www.reading.ac.uk/centaur}

\section{CentAUR}

Central Archive at the University of Reading

Reading's research outputs online 


\title{
The diminished effect of index rebalances
}

\author{
Konstantina Kappou*
}

This draft: April 2018

\begin{abstract}
The author revisits the strategy of trading S\&P 500 index re-compositions under the pre- and post-crisis financial environments, proving that the return structure has significantly changed. The results show for the first time, that there are currently no tradable abnormal returns between announcement and event dates in the post-crisis sample period, indicating smoother rebalancing mechanisms by bank's client facing desks and better services for passive end-investors. The newly added firms inflate the S\&P 500 index by less than 10 basis points per year. The results could be attributed to improved execution algorithms used by the banks, and potentially to the new regulatory reforms in the sector, which prevents financial institutions from taking large trading positions with their balance sheets.
\end{abstract}

JEL classification: G14

Keywords: index rebalancing, passive investment, S\&P 500, additions, index funds

*ICMA Centre, Henley Business School, University of Reading, Whiteknights Campus, Reading, RG6 6BA, United Kingdom

k.kappou@icmacentre.ac.uk 
Following the global credit crisis and the near collapse of the banking system, regulators and policymakers forced significant change upon the banking industry. Proprietary businesses once intertwined amongst customer facing businesses were no longer permitted within investment banks and were forced to find a different sponsor on the buy side. Predominantly hedge funds converted this liquidity pool, resulting in an unchanged supply to the investment managers. The customer facing businesses now left to bridge their short fall in revenue, aggressively sold direct market access products to many of the passive investment managers in house traders, making execution impact far more efficient.

This study revisits the strategy of trading S\&P 500 index re-compositions under the new financial environment, that have historically been perceived as profit making opportunities by banks and active traders. After taking into consideration overnight and intra-day abnormal returns, this work analyses the price effects of S\&P 500 index additions and the magnitude of the inflated index level, following a change in the constituents, on a yearly basis. Although the story of buying adds and selling deletes is far from new, the return structure has transformed significantly post the financial crisis and the regulation changes. Results show for the first time that tradable returns are non-existent following October 2008, and in contrast to previous research findings, there are currently no available profit opportunities. An important finding is that there are no abnormal returns during the date of event, indicating better index rebalancing services for passive end-clients. S\&P 500 index re-compositions cost less than 10 basis points per year to the end-investor on average.

The diminished effects of index rebalancing are unarguably a result of better market 
knowledge by market participants. In particular, stock analysts may have become better at predicting the stocks involved in the index re-compositions (although in the case of S\&P500, the rebalancing dates are not known in advance), and program trading desks may have improved their algorithm execution services, providing better market stability for the index and its new constituents. Moreover, the fact that the results are insignificant post the crisis could also support the argument that the new regulatory reforms may have helped in preventing financial institutions from taking large trading positions with their balance sheets. As a consequence, any potential conflict of interest that perhaps may have existed between client facing desks and end-investors during index-rebalancing periods is now eliminated.

The above results are good news for the passive community, proving a price discovery mechanism far more efficient than before, with negligible profits for arbitrageurs and mild effects on the overall index level. The findings of this study are in line with the rapid regulatory changes in banking infrastructure.

\section{Index announcement policies}

The aim of trading index re-compositions is to benefit from a price increase in the added stock and a price decrease in the deleted stock following the event however, the trading strategy depends on the announcement policy of the index provider. There are generally two types of announcement policies; the first one involves index changes whose event dates are pre-determined. The rebalancing dates are known to the market, (e.g. those of FTSE, Russell, and MSCI indices, amongst others) and the aim 
is to anticipate the names of the stocks involved in the change, and take the relevant positions well before the event. For this type of announcement policy, the criteria for becoming an index member are well defined and made publicly available. In the case of FTSE 100 rebalances for example, where the main criterion is the company's capitalization, the anticipation of the event is a simple issue. Consequently, the market is well prepared for these events and the edge of the trader is limited. The second category involves indices, whose constitution is subject to change at any point in time, whenever necessary. The Standard and Poor's indices follow this policy and as a result, events are much more difficult to anticipate and criteria for addition to the index could be subjective, resulting to a more "opaque" process. This study relates to the second category of index announcement policy.

\section{The history of S\&P index re-compositions}

The "S\&P Game", as Beneish and Whaley have successfully characterized it in 1997, has its roots back in 1976; prior to that date, information about S\&P 500 recomposition events was only occasional 1 and reported to the "S\&P Outlook". After 1976, the index providers initiated the Overnight Notification Service, which allowed subscribers to be notified about index re-compositions the evening of the day that the change was decided, and the change taking place the following day. To alleviate significant price pressures on the stocks involved, the index committee changed the announcement policy again in 1989, and changes were pre-announced an average of five days before the event date.

\footnotetext{
${ }^{1}$ Index changes were published every three to six months. The Wall Street Journal published index compositions very rarely.
} 
The above changes and the fact that the committee takes into account a set of other factors (e.g. financial stability, sector representation, trading activity and free float amongst others) made the anticipation of events far more challenging. Companies that meet the criteria are entered in the Replacement Pool, a pre-selected list of firms eligible for addition. Entering the Pool does not guarantee entry to the S\&P 500 and firms may be removed if they no longer meet the criteria. The reason for a rebalance is mainly caused by the fact that a firm needs to be deleted, which is why the previous literature has been mostly concentrated on added companies. The sample of deletions is almost always biased by other events, including restructuring, bankruptcy, merger and acquisition, making it difficult to collect a sample of "pure" deletions, i.e. with the addition being the driver (reason) of the re-composition event rather than the deletion. Hence, the findings of this work are exclusively focusing on additions to the index.

\section{Selected previous findings}

Due to the advent of index tracking which has its roots in 1976, index-rebalancing events were under close scrutiny, and their effects have been analyzed across the world. The S\&P 500 index effect has been historically the most attractive, not only due to the nature of the announcement policy, but also due to the enormous amount of assets tied to the index.

Beneish and Whaley (1996) were the first to examine the effects of the new announcement policy that took place in 1989 and allowed for an average five-day 
window between announcement and event. They found a permanent price increase of circa $4 \%$, with the average increase being greater under the new announcement policy. It was apparent that profitable opportunities aroused for active traders, who were buying the stock on announcement date and selling it at a premium to index fund managers on event date. Index funds generally prefer to wait until the change becomes effective, in order to minimize their tracking error. The more the money tied to the index, the more the potential for high returns due to increased trading volume, causing a larger price effect. As Pruitt and Wei proved in 1989, there is a positive relation between the abnormal return on the day after announcement and the net change in institutional ownership.

While there is a consistent strain of literature that has thoroughly proven significant price and volume effects following S\&P 500 index changes, the theories underlying the reasons of these effects are different, depending on whether the price and trading volume increases are temporary or permanent, the module used for estimation of abnormal returns and the different sample period. Previous findings are in support of five different hypotheses about the price (and volume) performance of the firms involved in an index re-composition event; the Price Pressure Hypothesis supporting temporary changes in price and trading volume (Harris and Gurel, 1986), the Imperfect Substitutes/Downward-Sloping Demand Curve for Stocks Hypothesis supporting permanent changes in prices and temporary changes in trading volume (Shleifer, 1986), the Information Content Hypothesis supporting permanent changes in prices and temporary changes in trading volume (Dhillon and Johnson, 1991), the Liquidity Cost Hypothesis arguing for permanent changes in prices and trading volume (Edmister et al, 1994 and 1996) and the Market Segmentation/Investor 
Recognition Hypothesis assuming asymmetric effects between additions and deletions (Chen et al, 2004).

The impact of index re-compositions has also been examined worldwide and for indices such as the FTSE 100 (Mazouz and Saadouni, 2007), the MSCI (Chakrabarti et al, 2002), the NIKKEI 225 (Liu, 2006), the TSE (Kaul et al, 2000), the Russell 2000 (Madhavan, 2003), the DAX (Deininger et al, 2000), the AEX (Doeswijk, 2005) and the DJIA (Beneish and Gardner, 1995). Recent work has also looked at the social index effect by looking at the effects of KLD MSCI Social index re-compositions to prove whether investors are sensitive about social responsibility and whether this is reflected in their investments (Kappou and Oikonomou, 2016).

The purpose of this study is neither to establish evidence for one of the aforementioned hypotheses, nor to examine long-term firm performance in general. The focus of this work is to answer three important questions; first, to determine whether the strategy of trading S\&P 500 additions is still lucrative for proprietary desks or other active market participants, assuming there is no anticipation or speculation of the upcoming events (i.e. that a trading position is originated after the announcement of the event). Second, to establish to what extent the 2008 financial meltdown, better execution algorithms and regulatory reforms may have affected the trading behavior of banks' client facing desks during rebalancing periods, and hence improved market efficiency and passive end-investor services. Third, to ascertain the hidden cost of "being passive", by looking at the level that the newly added firms inflate the index on a yearly basis, due to their better stock price performance just before their inclusion in the S\&P 500. 
The following section analyses the specifics of the trading strategy around the event window, given the timing of addition announcement and the period until the actual event, assuming no anticipation of the upcoming index re-composition.

\section{The S\&P 500 re-composition event window}

The S\&P index committee announces future index re-compositions on the Standard and Poor's website. The press release is out after the market close, making it impossible for market participants to trade immediately, i.e. in the evening of the announcement date (AD). The first potential trading opportunity takes place in the morning of the day after $(\mathrm{AD}+1)$. Therefore, a calculation of a close-to-close abnormal return from $\mathrm{AD}$ to $\mathrm{AD}+1$ would be irrelevant to active traders, since only the open-to-close abnormal return of $\mathrm{AD}+1$ is tradable. The actual index change takes place on the event date (ED), which follows on average five days after announcement. The change becomes effective at the close of business of the event date, and the S\&P trades under its new composition in the morning of the day after $(E D+1)$. The socalled "S\&P Game" assumes that arbitrageurs can benefit from index recompositions, by buying the added stock just after announcement and selling it to the index funds on the effective date.

Measuring abnormal return performance on a market close-to-market close basis cannot show whether active traders can achieve profits by trading the added stocks around the event period. This can only be determined if the analysis includes intraday 
(and overnight) stock price performance. Although previous research has extensively covered the effects of additions and deletions to the S\&P 500 on price and trading volume, there were only a few studies that focused on tradable returns.

Beneish and Whaley (1996 and 2002) examined overnight returns for two different sub-periods to measure the part of the stock price increase that is non-tradable. They reported an increase in the overnight performance from the evening of announcement date (AD) until the morning of the day after (AD+1 open). For the first sub-period the overnight return was $2.46 \%$ with an intraday return the day after of $-0.6 \%$ and for the second sub-period the overnight return increased to $5.84 \%$, whereas the intraday return of the day after decreased to $-0.85 \%$. Despite the fact that there were no positive tradable abnormal returns during the first day after announcement, there was an abnormal return between announcement and event of approximately $5 \%$.

More than a decade later, Kappou et al (2010), shed light not only to overnight returns, which were of similar levels to those of Beneish and Whaley, but also to tickby-tick abnormal returns and trading volumes, which were examined for the first time in the S\&P 500 index effect literature. More specifically, they defined a trading strategy by taking the relevant short and long positions in the added companies resulting in a profit of $7 \%$ on average (excluding transaction costs).

This study revisits the above findings in light of the new market developments post the financial crisis, that have affected the activity of proprietary traders and banks' client facing desks. First, an analysis of close-to-close, intraday and overnight abnormal returns presents the current effects on price performance and tradable 
profits around index re-compositions. Second, the sample is split into two sub-periods to establish whether the financial crisis followed by the new regulatory reforms has affected trading behavior and market efficiency. Third, this work measures the extent by which the S\&P 500 index is inflated by the newly added stocks through time, before passive investors have the opportunity to invest in the new index composition.

\section{Methodology and Data}

\section{Methodology}

The effects of S\&P re-compositions have been historically measured by event study methodologies using daily data. Previous research has been using various forms of abnormal return calculations during the period where the event takes place (also referred to as event window). A common method refers to Market Risk-Adjusted Returns. The systematic risk-adjusted model is similar to a one-factor model and assumes that all firms linearly depend on the market portfolio. The model parameters are calculated based on an estimation period taken from a sample of data outside the event window, either before or after the event, or a combination of the two. The Market Risk-Adjusted approach has been adapted in the studies of Goetzmann and Garry (1986), Harris and Gurel (1986), Shleifer (1986), Lamoureux and Wansley (1987), Jain (1987), Dhillon and Johnson (1991), Edmister et al (1994), Erwin and Miller (1998) and Malkiel and Radisich (2001).

Another method of calculating abnormal returns is the Market Adjusted Return approach, where the stock's abnormal return is regarded as the difference between the stock's return and that of the benchmark on a given trading day. This is a more 
straightforward process and relies on the assumption that the systematic risk of all stocks are equal to unity, and is adopted in this study for the following four reasons; firstly, the S\&P 500 members are companies of very large market capitalization in line with the index inclusion criteria. It would be therefore expected that their systematic risk would be very close to unity $^{2}$. Secondly, due to the fact that an analysis is also performed based on open-to-close and overnight abnormal returns, obtaining two sets of coefficients for each type of abnormal return would complicate the results without adding any valuable benefits. Thirdly, there is evidence of bias in the selection of the estimation period in order to obtain the regression coefficients, including the problem of non-stationary bias and the fact that firms are likely to perform well before the event, amongst others (see Jain, 1987). Lastly, the Market Adjusted approach has been used by a plethora of studies (see Woolridge and Ghosh, 1986; Beneish and Whaley, 1996 and 1997; Cusick, 2002; Wurgler and Zhuravskaya, 2002; Chen et al, 2004).

\section{Data}

Data of all the names, announcement and event dates were obtained by Standard and Poor's corporation from January 2002 until November 2013. Out of a total of 276 firms, 16 were removed due to lack of data and 32 were excluded, as they were not considered pure additions for two reasons; they were either a result of a break up of an existing index member company or of a reconstruction of the original company. If these firms were included, other effects than that of index membership could have affected price performance. The final sample consists of 228 additions. The data are

\footnotetext{
${ }^{2}$ To support this argument, a calculation of betas using a single-index model and a post-event estimation period of 1-year (following the method of Jain,1987), shows that the average level of the added firms' systematic risk is 1.16 .
} 
also split into two different sub-periods for further analysis before and after October $2008^{3}$. Stock and index closing and opening prices adjusted for dividends and corporate actions are obtained from Reuters.

An analysis is performed based on the construction of a short and long term event window. The short-term event window refers to the period from three weeks before the event (15 trading days) until four weeks after the event (20 trading days), whereas the long-term event window ends one year (252 trading days) after the event. Closeto-close and open-to-close abnormal returns are calculated using market-adjusted returns, as follows:

$$
A_{\text {CTCit }}=R_{C T C i t}-R_{C T C m t}
$$

where $A R_{C T C i}$ is the security's close-to close abnormal return at a particular time t, $R_{C T C i}$ is its realised ex post close-to-close return and $R_{C T C m}$ is the market's (S\&P 500) ex-post realised close-to-close return at that time t.

The close-to-close abnormal returns for all firms are then averaged against the total number of inclusion announcements $N$, for each day $t$ of the event window as:

$$
A A R_{C T C t}=\frac{1}{N} \sum_{i=1}^{N} A R_{C T C i t}
$$

\footnotetext{
${ }^{3}$ October 2008 is considered the most appropriate date to divide the sample given the series of financial events (Lehman bankrupty, Fannie Mae and Freddie Mac take over by the US governement, and Merill Lynch take over by Bank of America)
} 
where $A A R_{C T C t}$ is the average close-to-close abnormal return on day t, $t=\mathrm{AD}-15$ to $\mathrm{ED}+20$ for the short-term event window, and $t=\mathrm{AD}-15$ to $\mathrm{ED}+252$ for the long-term event window.

The t-statistics are reported for all daily abnormal returns and are defined by:

$$
t-\text { stat }=\frac{A A R_{C T C t}}{\hat{\mathrm{S}}\left(A A R_{C T C t}\right) / \sqrt{N}}
$$

where $A A R_{C T C i}$ is the average close-to-close abnormal return on day $\mathrm{t}$ and $\hat{\mathrm{S}}\left(A A R_{\text {CTCt }}\right)$ is the standard deviation of the abnormal returns on day $\mathrm{t}$.

Accordingly, the open-to-close abnormal return (OTC) is obtained by subtracting the open-to-close performance of the stock from that of the S\&P 500 index at each trading day. The overnight abnormal return (OVAR) is then derived by subtracting the open-to-close abnormal performance from the close-to-close abnormal performance, as shown in the following equations:

$$
\begin{gathered}
\text { ARoTCit }=\text { ROTCit }- \text { ROTCmt } \\
\text { OVAR }_{\text {it }}=\text { ARCTCit }- \text { AROTCit }
\end{gathered}
$$

where, in the case of the e.g. first day after the S\&P press release, $R_{C T C i t}$ and $R_{C T C m t}$ are the close-to-close returns between announcement day (AD) and the following day $(\mathrm{AD}+1)$ for the stock and the $\mathrm{S} \& \mathrm{P} 500$ respectively, $R_{\text {OTCit }}$ and $R_{\text {OTCmt }}$ are the open-to- 
close returns between $\mathrm{AD}+1$ open and $\mathrm{AD}+1$ close for the stock and the benchmark respectively, $A R_{C T C i t}, A R_{\text {OTCit }}$ are the close-to-close and open-to-close abnormal returns for each stock, respectively, and $O V A R_{i t}$ is the overnight (non-tradable) abnormal return between $\mathrm{AD}$ close and $\mathrm{AD}+1$ open for each firm. This date is of particular interest, as it reflects the efficiency of the market to reflect the increase in the price of the newly added firm, affecting the opportunity of tradable profits.

Although stocks belonging to the S\&P 500 are large value stocks with significant trading activity and efficient price discovery, it is important to note that opening prices need to be treated with caution, as they may not always reflect accurate estimates of the stock's current value and potentially affect the robustness of the findings. Opening prices experience higher volatility and a more negative autocorrelation pattern than closing prices, after taking into account information arrivals (Amihud and Mendelson, 1987 , Stoll and Whaley, 1990). This behavior may be attributed to traders overreacting to overnight information by trading quickly upon the market open and pushing prices away from their fundamental levels (Kim, 2013).

\section{Abnormal performance between announcement and event}

According to the rules of the S\&P 500 index Committee, changes are preannounced at an average of five days before the actual event. In the 2002-2013 sample, the shortest period between announcement date and effective date is one day (i.e. the event takes place the day following announcement) and the longest is twenty-seven days. As the number of firms with more than seven days between announcement and event 
radically diminishes, the daily average firm performance is not reported in the exhibits beyond $\mathrm{AD}+7 .{ }^{4}$

\section{Transaction Costs}

The above estimations of abnormal returns do not include transaction costs. Trading costs reflect the price impact of executing a transaction and depend on the type of the market, liquidity of stocks and timing of trades. Kappou et al 2010, argue that bid-ask spreads tend to be wider at the market close than during the trading day. In their study of S\&P 500 index additions for the period 1999-2000 using tick-by-tick data, they found that the bid-ask spread as a percentage of the mid-price was 45bps on average if calculated at the close, and only $12 \mathrm{bps}$ if calculated during the day. Based on these findings, the abnormal returns of this study could be affected by approximately up to 45 basis points for a round trip transaction (buy and sell) if trading costs were taken into account.

\section{Results}

An analysis of the price effects following addition to the S\&P 500 is presented in Exhibit I. Close-to-close abnormal returns are reported from fifteen trading days before the event announcement until four weeks after the actual event. There is no evidence of significant abnormal returns before announcement, apart from a marginal average price increase of $0.36 \%$ four days before. This result may suggest that the market may have not anticipated the event, consistent to the fact that S\&P 500 re-

\footnotetext{
${ }^{4}$ There are only 10 firms in the sample that were added to the index more than 7 days following announcement.
} 
composition dates are not known in advance. Another potential explanation could be that trading volume has absorbed any speculative pre-event activity or that trading has taken place well before the event with no market impact, or both of the above.

The first significant price jump takes place on the first day after announcement $(A D+1)$ and is of the magnitude of $3.01 \%$, which is highly significant. Following this date, there are no further significant abnormal returns, apart from the date that the event is effective (ED). Particularly, by the close of business of the event date (ED), there is a highly significant abnormal return of $0.53 \%$, indicating a price pressure potentially caused by index fund rebalancing over the last minutes of the trading day and/or the orders of the closing auction (see Kappou et al, 2010). Following this date, there is a series of negative returns for at least one month after the event, demonstrating a price reversal. The negative returns are statistically significant only on days $\mathrm{ED}+4$ and $\mathrm{ED}+12$. The reversal fully offsets the price increase that was accumulated since the date of announcement, resulting to the overall price effect being considered negligible.

When looking at the average long-term firm performance (Exhibit II), the average cumulative abnormal returns are of particular interest. There is a clear price reversal over the period of three months after inclusion, indicating that the importance of S\&P 500 index membership, previously considered as a seal of approval, is now insignificant. The S\&P index committee always argued that addition to the S\&P 500 should not be treated as information about the future prosperity of the firms however, the market has historically treated these events as evidence of superior future performance (see Jain, 1987, Jacques, 1988 and Denis et al, 2003). 
The above results are very different to those of previous studies. In particular, previous research (conducted using older samples/different time periods) reports significant abnormal performance not only on the first day after announcement, but also between announcement and event, allowing active traders to achieve profits at the expense of index trackers. Beneish and Whaley (1996) estimate an abnormal return of $2.52 \%$ from the close of $\mathrm{AD}+1$ until the close of $\mathrm{ED}$, while Kappou et al (2010) report a significant return of $4.3 \%$.

The second part of the results refers to the intraday and overnight abnormal performance for the whole sample and for two sub-periods, before and after the financial crisis. Exhibit III illustrates the short-term event window with close-to-close, open-to-close and overnight abnormal returns for the whole sample. It can be seen that the open-to-close abnormal return on the first day after announcement $(\mathrm{AD}+1)$ is negative and reaches $-0.22 \%$, a figure that is statistically insignificant. This indicates that all the price increase took place overnight, with an overnight abnormal return of $3.23 \%$ (i.e. from the close of announcement date (AD close) until the morning after (AD+1 morning)). In other words, an overnight abnormal return of $3.23 \%$ together with an open-to-close abnormal return of $-0.22 \%$ constitutes the $3.01 \%$ close-to-close abnormal return, that was reported in the previous analysis.

When looking at the two sub-samples (Exhibits IV and V) the pattern is similar for the pre-2008 sub-period with almost all the abnormal return taking place overnight (3.21\%), and a negligible intraday positive performance on $\mathrm{AD}+1(0.07 \%)$. When looking at the post-2008 sub-period, the overnight return still constitutes the major 
part of the abnormal return (3.25\%) but this time with a significant intraday price reversal on $\mathrm{AD}+1(-0.62 \%)$. All the above indicate important evidence of market efficiency and negligible tradable profits on the first day following announcement.

When looking at each of the dates beyond $\mathrm{AD}+1$, the close-to-close abnormal performance although insignificant for the whole sample (Exhibit III), is positive for the pre-2008 sample and negative for the post-2008 sample. Moreover, the close-toclose average cumulative abnormal returns (CARs) from $\mathrm{AD}+2$ until $\mathrm{AD}+7$ presented in Exhibit VI confirm that firm performance beyond $\mathrm{AD}+1$ and before $\mathrm{ED}$ was significantly positive for the pre-2008 period, whereas it was negative and insignificant for the post-2008 period. This is an important finding and indicates that the S\&P Game has become less popular after the crisis, and it is not causing further price pressures following announcement. Furthermore, the calculation of overnight and open-to-close abnormal returns confirms that the strategy of simply buying the added stock in the morning following the announcement date and selling it at the close of business of the event date does not generate any significant returns any longer.

The final date, which is of particular interest, is the event date (ED), as stocks have historically experienced price pressure specifically because of index fund rebalancing. In previous studies, the abnormal return of this date was always statistically significant (e.g. 1.67\% reported by Beneish and Whaley (1996) and 2.18\% by Kappou et al (2010)) and in fact, there was evidence that trading pressure was taking place over the last 5 minutes of the trading day (see Kappou et al, 2010). The results of this study show not only that the overall level of the close-to-close abnormal return for the 
event date has diminished in absolute terms relative to previous studies $(0.53 \%$ as shown in Exhibit III), but also that it is statistically significant and positive in the pre2008 period (just under 1\% as shown in Exhibit IV) and statistically insignificant and negligible in the post-2008 period $(-0.10 \%$, as shown in Exhibit V). In other words, a negligible close-to-close abnormal return during the event date for the post-2008 sample provides evidence of smoother rebalancing mechanisms by banks' program trading desks, and indicates that passive end-investors are not affected from the price pressures of the rebalancing orders that goes into the closing auction.

To summarize the findings, the above analysis argues about i) increased market efficiency (as the positive and significant overnight return from $A D$ close to $A D+1$ is non tradable, and there is only a mild correction the day after), ii) reduced interest in the "S\&P" game by active traders (since the abnormal returns during the days between the morning of $\mathrm{AD}+1$ and $\mathrm{ED}$ are low and no longer statistically significant) and iii) improved, smoother rebalancing mechanisms and better execution algorithms by banks' client facing desks on behalf of passive investors, but only for the postfinancial crisis sample (due to the insignificant and non-existent abnormal returns on the event date). The third finding is of great importance as it could also support the argument that the post-crisis regulatory framework, may have helped to an extent in achieving better services for passive investors. In particular, the imposed restrictions on banks' balance sheets may have prevented banks from taking large trading bets and may have removed potential conflicts of interest between banks' orders and client orders (execution orders), during rebalancing periods. 
The final part of this study refers to the effects of the inflated added stocks on index performance. These effects are not reflected in the reported index value, as the price increase is realized before each firm becomes an index member. They can be considered as a hidden re-balancing cost, that negatively affects passive index performance through time.

The extent to which each added stock inflates the S\&P 500 can be calculated by using the firms' overall abnormal performance from the announcement date until the date of event, adjusted by the relative market capitalization of the firm versus that of the index at the time of inclusion. Market capitalization data are collected from Reuters for all firms in the sample, and are used to estimate the weight of each added company to the overall index at the time of inclusion. Exhibit VII shows that the average index increase on an annual basis over the period of 2002-2013 is just under 10 basis points per year, indicating a minor effect on long-term index performance. When looking at the two subsamples (Exhibit VIII), the average annual cost drops by more than half over the post crisis sub-period, providing further evidence of market efficiency and better index rebalancing services for passive clients.

\section{Concluding Remarks}

For the last decade, the rapid increase in the efficiency, liquidity and transparency of financial markets, the more-informed index fund managers, and the post-crisis scrutiny of financial transactions and regulatory restrictions, have changed the abnormal return patterns of the added stocks around S\&P 500 index re-composition events. This study focuses on close-to-close, intraday and overnight abnormal returns 
to ascertain i) whether there are tradable profits available to active traders ii) whether a better market information, a more effective order execution or the post-crisis regulatory framework may have improved trading behavior and bank's client services during index rebalancing periods and iii) what is the overall index inflation caused by the newly added stocks. The results show that passive investors are currently much better serviced with a minimum impact on their portfolio performance.

In particular, the results show for the first time that there are no available tradable abnormal returns between announcement and event apart from the effective date. When looking at the post 2008 subsample, the abnormal returns on the effective date are insignificant, indicating that portfolio rebalancing does not cause any price shocks, and hence passive end-investors are better serviced. Overall, the rebalances inflate the index only by 9 basis points per year. Lastly, the long-term performance of the added stocks indicates a full price reversal, discarding all theories regarding permanent price pressure, valuable information content in S\&P 500 re-compositions and any privileges for index member firms.

Although the strategy of trading index re-balances and in particular, those of the S\&P 500 , represents only a very small fraction of the current global proprietary trading business, its effectiveness can be easily quantified and was analyzed extensively in this study; however, the magnitude by which the new market developments and regulatory framework will impact the remaining, more advanced segments of the proprietary sector, will only become known overtime... 


\section{References}

Amihud Y. and Mendelson H. (1987) "Trading Mechanisms and Stock Returns: An Empirical Investigation”. Journal of Finance 42, (3), pp. 533-553.

Beneish M. and Gardner J. (1995) "Information Costs and Liquidity Effects from Changes in the Dow Jones Industrial Average List." Journal of Financial and Quantitative Analysis 30, (1), pp. 135-157.

Beneish M. and Whaley R. (1996) "An Anatomy of the "S\&P Game": The Effects of Changing the Rules." Journal of Finance 51, (5), pp. 1909-1930.

Beneish M. and Whaley R. (1997) "A Scorecard from the S\&P Game: Can I Play?" Journal of Portfolio Management 23, (2), pp. 16-23.

Beneish M. and Whaley R. (2002) "S\&P 500 Index Replacements: A New Game in Town.” Journal of Portfolio Management 29, (1), pp. 51-60.

Chakrabarti R., Huang W., Jayaraman N. and Lee J. (2002) "The Index effect on Stock Prices and Trading Volumes: International Evidence." Working Paper Series, Georgia Tech Center for International Business Education and Research, 2002- 2003.

Chen H., Noronha G. and Singal V. (2004) "The Price Response to the S\&P 500 Additions and Deletions: Evidence of Asymmetry and a New Explanation." Journal of Finance 59, (4), pp. 1901-1929.

Cusick P. (2002) "Price effects of Addition or Deletion from the Standard and Poor's 500 Index: Evidence of Increasing Market Efficiency." Financial Markets, Institutions and Instruments 11, (4), pp. 349-383.

Deininger C., Kaserer C. and Roos S. (2000) "Stock Price Effects associated with Index Replacements in Germany." Working Paper No 7, Free University of BozenBolzano.

Denis D., McConnell J., Ovtchinnikov A. and Yu Y. (2003) "S\&P 500 Index Additions and Earnings Expectations.” Journal of Finance 58, (5), pp. 1821-1840.

Dhillon U. and Johnson H. (1991) "Changes in the Standard and Poor's 500 List." Journal of Business 64, (1), pp. 75-85.

Doeswijk R. (2005) “The Index Revision Party." International Review of Financial Analysis 14, (1), pp. 93-112.

Edmister R., Graham S. and Pirie W. (1994) "Excess Returns of Index Replacement Stocks: Evidence of Liquidity and Substitutability." Journal of Financial Research 17, (3), pp. 333-346. 
Edmister R., Graham S. and Pirie W. (1996) "Trading Cost Expectations: Evidence from S\&P 500 Index Replacement Stock Announcements." Journal of Economics and Finance 20, (2), pp. 75-85.

Erwin G. and Miller J. (1998) "The Liquidity Effects Associated with Addition of a Stock to the S\&P 500 Index: Evidence from Bid/Ask Spreads." The Financial Review 33, pp. 131-146.

Goetzmann W. and Garry M. (1986) "Does Delisting Affect Stock Price?" Financial Analyst Journal 42, (2), pp. 64-69.

Harris L. and Gurel E. (1986) "Price and Volume Effects Associated with Changes in the S\&P 500 List: New Evidence for the Existence of Price Pressures." Journal of Finance 41, (4), pp. 815-829.

Jacques W. (1988) "The S\&P 500 Membership Anomaly, or Would You Join this Club?” Financial Analyst Journal 44, (6), pp. 73-75.

Jain P. (1987) "The Effect on Stock Price of Inclusion or Exclusion from the S\&P 500.” Financial Analysts Journal 43, (1), pp. 58-65.

Kappou K., Brooks C. and Ward C.W. (2010) "The S\&P 500 index effect reconsidered: Evidence from overnight and intraday stock price performance and volume." Journal of Banking and Finance 34, (1), pp. 116-126.

Kappou K. and Oikonomou I. (2016) "Is there a Gold Social Seal? The Financial Effects of Additions to and Deletions from Social Stock Indices." Journal of Business Ethics 133, (3), pp. 533-552.

Kaul A., Mehrotra V. and Morck R. (2000) "Demand Curves For Stocks Do Slope Down: New Evidence From An Index Weights Adjustment." Journal of Finance 55, (2), pp. 893-912.

Kim S. (2013) “The Timing of Opening Trades and Pricing Errors". Financial Management, 42, (3), pp. 503-516.

Lamoureux C. and Wansley J. (1987) "Market Effects of Changes in the Standard and Poor's 500 Index.” The Financial Review 22, (1), pp. 53- 69.

Liu S. (2006) "The Impacts of Index Rebalancing and their Implications: Some New Evidence from Japan." Journal of International Financial Markets, Institutions and Money 16, (3), pp. 246-269.

Madhavan A. (2003) “The Russell Reconstitution Effect." Financial Analysts Journal 59, (4), pp. 51-64.

Malkiel B. and Radisich A. (2001) "The Growth of Index Funds and the Pricing of Equity Securities." Journal of Portfolio Management 27, (2), pp. 9 -21. 
Mazouz K. and Saadouni B. (2007) "The price effects of FTSE 100 index revision: what drives the long-term abnormal return reversal?" Applied Financial Economics 17, (6), pp. 501-510.

Pruitt S. and Wei J. (1989) "Institutional Ownership and Changes in the S\&P 500." Journal of Finance 44, (2), pp. 509-513.

Shleifer A. (1986) "Do Demand Curves for Stocks Slope Down?" Journal of Finance 41, (3), pp. 579-590.

Stoll H. and Whaley R. (1990) " Stock Market Structure and Volatility." Review of Financial Studies 3, (1), pp. 37-71.

Woolridge R. and Ghosh C. (1986) "Institutional Trading and Security Prices: The Case of Changes in the Composition of the S\&P 500 Index." Journal of Financial Research 9, (1), pp. 13- 24.

Wurgler J. and Zhuravskaya E. (2002) "Does Arbitrage Flatten Demand Curves for Stocks?” Journal of Business 75, (4), pp. 583-608.

Exhibit I: Average Abnormal Firm Performance upon inclusion -short-term event window

\begin{tabular}{ccc}
\hline \hline Date & Abnormal Return & t-statistic \\
\hline \hline AD-15 & $0.10 \%$ & 0.62 \\
AD-14 & $-0.03 \%$ & -0.18 \\
AD-13 & $-0.01 \%$ & -0.07 \\
AD-12 & $0.10 \%$ & 0.80 \\
AD-11 & $-0.06 \%$ & -0.46 \\
AD-10 & $-0.24 \%$ & -1.75 \\
AD-9 & $-0.20 \%$ & -1.43 \\
AD-8 & $0.29 \%$ & 1.67 \\
AD-7 & $-0.03 \%$ & -0.06 \\
AD-6 & $0.18 \%$ & 0.97 \\
AD-5 & $0.08 \%$ & 0.49 \\
AD-4 & $\mathbf{0 . 3 6 \%}$ & $\mathbf{2 . 3 9}$ \\
AD-3 & $0.06 \%$ & 0.45 \\
AD-2 & $0.07 \%$ & 0.51 \\
AD-1 & $0.02 \%$ & 0.13 \\
AD & $-0.15 \%$ & -1.02 \\
AD+1 & $\mathbf{3 . 0 1 \%}$ & $\mathbf{1 5 . 9 3 *}$ \\
AD+2 & $0.14 \%$ & 0.89 \\
AD+3 & $-0.08 \%$ & -0.50 \\
AD+4 & $0.06 \%$ & 0.30 \\
AD+5 & $0.25 \%$ & 1.18 \\
AD+6 & $-0.08 \%$ & -0.34
\end{tabular}




\begin{tabular}{ccc} 
AD+7 & $0.39 \%$ & 0.96 \\
ED & $\mathbf{0 . 5 3 \%}$ & $\mathbf{2 . 8 6}$ \\
ED+1 & $-0.26 \%$ & -1.73 \\
ED+2 & $-0.22 \%$ & -1.58 \\
ED+3 & $-0.26 \%$ & -1.79 \\
ED+4 & $-\mathbf{0 . 2 6 \%}$ & $\mathbf{- 1 . 9 9}$ \\
ED+5 & $-0.18 \%$ & -1.24 \\
ED+6 & $-0.23 \%$ & -1.68 \\
ED+7 & $0.02 \%$ & 0.17 \\
ED+8 & $-0.07 \%$ & -0.45 \\
ED+9 & $-0.17 \%$ & -1.30 \\
ED+10 & $-0.17 \%$ & -1.10 \\
ED+11 & $-0.13 \%$ & -0.88 \\
ED+12 & $-\mathbf{0 . 3 0 \%}$ & $-\mathbf{2 . 0 9}$ \\
ED+13 & $-0.24 \%$ & -1.63 \\
ED+14 & $-0.05 \%$ & -0.39 \\
ED+15 & $-0.11 \%$ & -0.85 \\
ED+16 & $-0.03 \%$ & -0.20 \\
ED+17 & $-0.11 \%$ & -0.89 \\
ED+18 & $-0.21 \%$ & -1.86 \\
ED+19 & $0.11 \%$ & 0.73 \\
ED+20 & $-0.02 \%$ & -0.15 \\
\hline \hline
\end{tabular}

Notes: An asterisk denotes statistical significance at $5 \%$ level or above.

Exhibit II: Cumulative average abnormal long-term firm performance upon inclusion

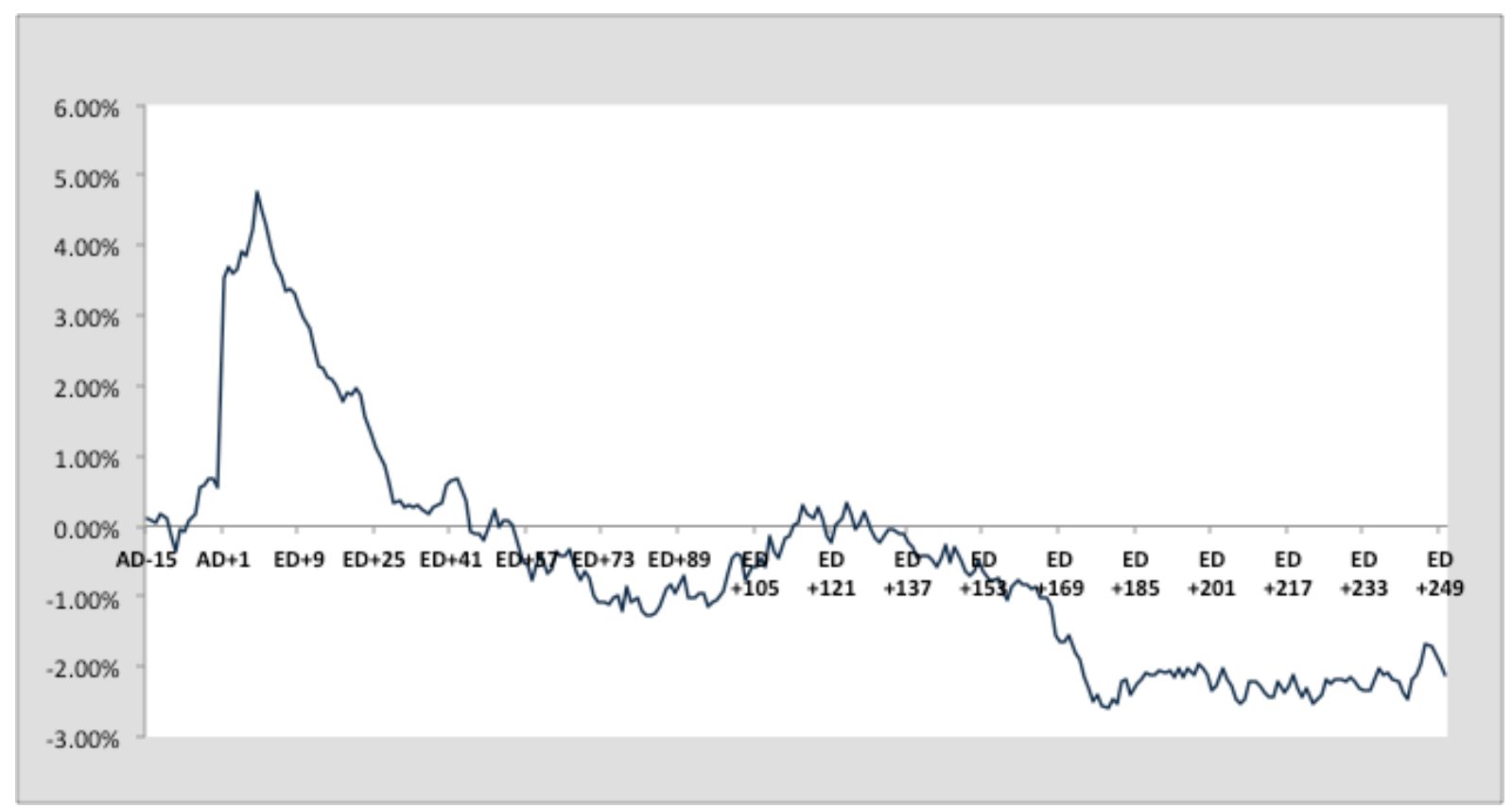


Exhibit III: Close-to-close, open-to-close and overnight abnormal returns, whole sample

\begin{tabular}{|c|c|c|c|c|c|c|c|c|c|c|}
\hline $\begin{array}{c}\text { Whole sample } \\
\text { period }\end{array}$ & AD & $A D+1$ & $A D+2$ & $A D+3$ & $A D+4$ & $A D+5$ & $A D+6$ & $A D+7$ & $\ldots .$. & ED \\
\hline Close to Close AR & $-0.15 \%$ & $3.01 \%$ & $0.14 \%$ & $-0.08 \%$ & $0.06 \%$ & $0.25 \%$ & $-0.08 \%$ & $0.39 \%$ & & $0.53 \%$ \\
\hline t-statistic & -1.02 & $15.93^{*}$ & 0.89 & -0.50 & 0.30 & 1.18 & -0.34 & 0.96 & & $2.86^{*}$ \\
\hline Open to Close AR & $-0.12 \%$ & $-0.22 \%$ & $0.09 \%$ & $0.03 \%$ & $0.14 \%$ & $0.18 \%$ & $-0.55 \%$ & $0.21 \%$ & & $0.08 \%$ \\
\hline t-statistic & -0.95 & -1.61 & 0.58 & 0.23 & 0.75 & 0.70 & -1.82 & 0.53 & & 0.43 \\
\hline Overnight AR & $-0.03 \%$ & $3.23 \%$ & $0.05 \%$ & $-0.12 \%$ & $-0.08 \%$ & $0.08 \%$ & $0.47 \%$ & $0.19 \%$ & & $0.45 \%$ \\
\hline t-statistic & -0.31 & 25.09* & 0.68 & -1.14 & -0.84 & 0.66 & $2.42^{*}$ & 1.26 & & $4.87^{*}$ \\
\hline
\end{tabular}

Notes: An asterisk denotes statistical significance at 5\% level or above.

Exhibit IV: Close-to-close, open-to-close and overnight abnormal returns, 2002- October 2008 sub-period

\begin{tabular}{|c|c|c|c|c|c|c|c|c|c|c|}
\hline $\begin{array}{l}\text { Pre-Oct } 2008 \\
\text { sub-period }\end{array}$ & AD & $A D+1$ & $A D+2$ & $A D+3$ & $A D+4$ & $A D+5$ & $A D+6$ & $A D+7$ & $\ldots$ & ED \\
\hline Close to Close AR & $-0.19 \%$ & $3.28 \%$ & $0.28 \%$ & $0.20 \%$ & $0.34 \%$ & $0.56 \%$ & $0.07 \%$ & $0.59 \%$ & & $0.96 \%$ \\
\hline t-statistic & -0.96 & $14.26 *$ & 1.46 & 1.02 & 1.18 & 1.83 & 0.22 & 0.97 & & $4.19 *$ \\
\hline Open to Close AR & $-0.06 \%$ & $0.07 \%$ & $0.12 \%$ & $0.30 \%$ & $0.39 \%$ & $0.46 \%$ & $-0.52 \%$ & $0.29 \%$ & & $0.44 \%$ \\
\hline t-statistic & -0.38 & 0.37 & 0.64 & 1.62 & 1.54 & 1.30 & -1.18 & 0.48 & & 1.88 \\
\hline Overnight AR & $-0.14 \%$ & $3.21 \%$ & $0.16 \%$ & $-0.10 \%$ & $-0.05 \%$ & $0.10 \%$ & $0.59 \%$ & $0.31 \%$ & & $0.52 \%$ \\
\hline t-statistic & -0.84 & $21.49 *$ & 1.52 & -0.79 & -0.39 & 0.67 & $2.04 *$ & 1.39 & & 4.29* \\
\hline
\end{tabular}

Notes: An asterisk denotes statistical significance at 5\% level or above. 
Exhibit V: Close-to-close, open-to-close and overnight abnormal returns, October 2008-

November 2013 sub-period

\begin{tabular}{|c|c|c|c|c|c|c|c|c|c|c|}
\hline $\begin{array}{c}\text { Post- Oct } 2008 \text { sub- } \\
\text { period }\end{array}$ & AD & $A D+1$ & $A D+2$ & $A D+3$ & $A D+4$ & $A D+5$ & $A D+6$ & $A D+7$ & $\ldots$ & ED \\
\hline Close to Close AR & $-0.09 \%$ & $2.63 \%$ & $-0.03 \%$ & $-0.41 \%$ & $-0.21 \%$ & $-0.10 \%$ & $-0.30 \%$ & $0.11 \%$ & & $-0.10 \%$ \\
\hline t-statistic & -0.41 & $8.34 *$ & -0.10 & -1.53 & -0.80 & -0.34 & -0.85 & 0.22 & & -0.34 \\
\hline Open to Close AR & $-0.20 \%$ & $-0.62 \%$ & $0.05 \%$ & $-0.27 \%$ & $-0.09 \%$ & $-0.15 \%$ & $-0.59 \%$ & $0.10 \%$ & & $-0.45 \%$ \\
\hline t-statistic & -1.02 & $-3.05^{*}$ & 0.21 & -1.15 & -0.34 & -0.41 & -1.61 & 0.20 & & -1.42 \\
\hline Overnight AR & $0.11 \%$ & $3.25 \%$ & $-0.08 \%$ & $-0.14 \%$ & $-0.11 \%$ & $0.05 \%$ & $0.29 \%$ & $0.02 \%$ & & $0.35 \%$ \\
\hline t-statistic & 0.74 & $14.28 *$ & -0.77 & -0.83 & -0.76 & 0.26 & 1.33 & 0.10 & & $2.42 *$ \\
\hline
\end{tabular}

Notes: An asterisk denotes statistical significance at 5\% level or above.

Exhibit VI: Summary of rebalancing effect

\begin{tabular}{l|ccc}
\hline \hline & $\begin{array}{c}\text { Close to } \\
\text { Close } \\
\text { AR on AD+1 }\end{array}$ & $\begin{array}{c}\text { Close to Close } \\
\text { CAR, } \\
\text { AD+2 to AD+7 }\end{array}$ & $\begin{array}{c}\text { Close to close } \\
\text { AR on ED }\end{array}$ \\
\hline \hline & & & \\
Whole Sample & $\mathbf{3 . 0 1 \%}$ & $0.23 \%$ & $\mathbf{0 . 5 3 \%}$ \\
t-statistic & $\mathbf{1 5 . 9 3 *}$ & 0.98 & $\mathbf{2 . 8 6 *}$ \\
& & & \\
& & & \\
$\begin{array}{l}\text { Pre- Oct 2008 } \\
\text { sub-period }\end{array}$ & $\mathbf{3 . 2 8 \%}$ & $\mathbf{0 . 8 7 \%}$ & $\mathbf{0 . 9 6 \%}$ \\
t-statistic & $\mathbf{1 4 . 2 6 *}$ & $\mathbf{3 . 1 7} *$ & $\mathbf{4 . 1 9 *}$ \\
& & & \\
$\begin{array}{l}\text { Post- Oct 2008 } \\
\text { sub-period }\end{array}$ & $\mathbf{2 . 6 3 \%}$ & $-0.57 \%$ & $-0.10 \%$ \\
t-statistic & $\mathbf{8 . 3 4 *}$ & -1.49 & -0.34 \\
\hline \hline
\end{tabular}

Notes: An asterisk denotes statistical significance at 5\% level or above. 
Exhibit VII: The effects of index re-compositions on the overall index performance on an annual basis- whole sample

\begin{tabular}{ccc}
\hline \hline Year & $\begin{array}{c}\text { Number of } \\
\text { events }\end{array}$ & Inflation rate \\
\hline \hline 2002 & 19 & $0.30 \%$ \\
2003 & 8 & $0.00 \%$ \\
2004 & 14 & $0.04 \%$ \\
2005 & 17 & $0.05 \%$ \\
2006 & 25 & $0.19 \%$ \\
2007 & 32 & $0.09 \%$ \\
2008 & 36 & $0.16 \%$ \\
2009 & 22 & $0.05 \%$ \\
2010 & 15 & $0.11 \%$ \\
2011 & 15 & $0.05 \%$ \\
2012 & 14 & $0.01 \%$ \\
2013 & 11 & $0.03 \%$ \\
\hline Totals & $\mathbf{2 2 8}$ & $\mathbf{1 . 0 9 \%}$ \\
\hline \hline Average annual & & $\mathbf{0 . 0 9 \%}$ \\
cost & & \\
\hline \hline
\end{tabular}

Exhibit VIII: The effects of index re-compositions on the overall index performance on an annual basis- two sub-samples

\begin{tabular}{cc}
\hline \hline Sample Period & $\begin{array}{c}\text { Average Annual } \\
\text { Cost }\end{array}$ \\
\hline \hline $2002-2008$ & $0.12 \%$ \\
$2008-2013$ & $0.05 \%$ \\
\hline \hline
\end{tabular}

